\title{
BMJ Open Coronary heart disease, hypertension and use of biomass fuel among women: comparative cross-sectional study
}

\author{
Zafar Fatmi, ${ }^{\oplus 1,2}$ Georgia Ntani, ${ }^{2}$ David Coggon ${ }^{2}$
}

To cite: Fatmi Z, Ntani G, Coggon D. Coronary heart disease, hypertension and use of biomass fuel among women: comparative crosssectional study. BMJ Open 2019;9:e030881. doi:10.1136/ bmjopen-2019-030881

- Prepublication history and additional material for this paper are available online. To view these files, please visit the journal online (http://dx.doi. org/10.1136/bmjopen-2019030881).

Received 04 April 2019 Revised 06 July 2019 Accepted 09 July 2019
Check for updates

(c) Author(s) (or their employer(s)) 2019. Re-use permitted under CC BY-NC. No commercial re-use. See rights and permissions. Published by BMJ.

${ }^{1}$ Department of Community Health Sciences, Aga Khan University, Karachi, , Pakistan ${ }^{2}$ MRC Lifecourse Epidemiology Unit, University of Southampton, Southampton, UK

Correspondence to Professor Zafar Fatmi; zafar.fatmi@aku.edu

\begin{abstract}
Objectives To explore the associations of hypertension and coronary heart disease (CHD) with use of biomass fuel for cooking.

Design Comparative cross-sectional study.

Setting Rural villages in Sindh, Pakistan.

Participants Women aged $\geq 40$ years who had used biomass fuel for cooking for at least the last year $(n=436)$, and a comparison group $(n=414)$ who had cooked only with non-biomass fuel during the last year were recruited through door-to-door visits. None of those who were invited to take part declined.

\section{Primary and secondary outcome}

measures Hypertension was determined from blood pressure measurements and use of medication. CHD was assessed by three measures: history of angina (Rose angina questionnaire), previous history of 'heart attack', and definite or probable changes of CHD on ECG. Potentially confounding risk factors were ascertained by questionnaire and anthropometry. Associations of hypertension and CHD with use of biomass and other risk factors were assessed by logistic regression, and summarised by ORs with $95 \%$ Cls.
\end{abstract}

Results After adjustment for potential confounders, there was no association of hypertension (OR: $1.0,95 \% \mathrm{Cl} 0.8$ to 1.4) angina (OR: $1.0,95 \% \mathrm{Cl} 0.8$ to 1.4 ), heart attack (OR: $1.2,95 \% 0.7$ to 2.2) or ECG changes of CHD (OR: $0.8,95 \%$ $\mathrm{Cl} 0.6$ to 1.2) with current use of biomass for cooking. Nor were any associations apparent when analyses were restricted to long-term ( $\geq 10$ years) users and non-users of biomass fuel.

Conclusions A linked air monitoring study indicated substantially higher airborne concentrations of fine particulate matter in kitchens where biomass was used for cooking. It is possible that associations with CHD and hypertension were missed because most of the comparison group had used biomass for cooking at some time in the past, and risk remains elevated for many years after last exposure.

\section{INTRODUCTION}

Some three billion people across the globe use biomass fuel (such as wood, crop wastes, animal-dung and charcoal/coal) for cooking and heating. ${ }^{1}$ Burning of biomass fuels in inefficient stoves or open fires causes household air pollution (HAP) and leads to an estimated 3.8 million deaths per year globally. ${ }^{2}$

\section{Strengths and limitations of this study}

- The study was well-powered with a high response rate (93\%) from those invited to take part, and large contrasts between comparison groups in recent exposure to indoor air pollution.

- Comparisons were based on recent cooking practices, but some exposures may have changed since the onset of coronary heart disease.

- Many women who did not currently use biomass for cooking, had done so in the past and this may have obscured associations with health outcomes if effects of exposure persist long-term.

- Errors may have occurred in the assessment of outcome measures, biassing risk estimates towards the null.

- Recall of some potentially confounding factors may have been inaccurate, leading to uncontrolled residual confounding.

It primarily affects women and young children in low-/middle-income countries. Such women often work for $4-5$ hours per day in the kitchen, and with their young children may spend $90 \%$ of their time at home. ${ }^{23}$ About $77 \%$ of households in Africa and $60 \%$ in Southeast Asia use biomass fuel. ${ }^{1}$

The HAP from burning biomass consists of hundreds of health-damaging pollutants, but finer particles $\left(<2.5 \mu \mathrm{m}-\mathrm{PM}_{2.5}\right)$ and carbon monoxide are the major emissions, and have been studied most extensively. $\mathrm{PM}_{2.5}$ causes inflammation of the lungs and airways, and impairs immune responses. ${ }^{4}$ Concentrations of $\mathrm{PM}_{2.5}$ in kitchens and living rooms can be 100 times higher than the acceptable standard for ambient (outdoor) air. ${ }^{5}$ HAP predisposes to upper and lower respiratory tract infections among children, ${ }^{6-8}$ and also causes chronic obstructive pulmonary disease ${ }^{910}$ and lung cancer in adults. ${ }^{11-13}$ It has been linked with early foetal loss, preterm delivery and low-birthweight babies, ${ }^{14} 15$ and evidence is accumulating that it may also affect the physical and cognitive development of young children. ${ }^{16}$ 
In addition, several studies have suggested a hazard of coronary heart disease (CHD) from HAP exposure, but evidence for this is limited and inconclusive. ${ }^{17}{ }^{18}$ Several adverse cardiovascular outcomes have been studied, including acute coronary syndrome (myocardial infarction/unstable angina), CHD and high blood pressure. Two small scale case-control studies found significantly high risk of acute coronary syndrome with use of solid fuel. ${ }^{19}{ }^{20}$ In addition, a cohort study found an association between myocardial infarction and domestic use of coal among women in China. ${ }^{21}$ Lee and colleagues, ${ }^{22}$ in a large cross-sectional survey of adults in China, found a positive association with CHD. On the other hand, two large cohort studies, one in $\operatorname{Iran}^{23}$ and the other in Bangladesh, ${ }^{24}$ found no association with CHD, although it is unclear how potential confounders were taken into account in those investigations. Most studies have found significant positive associations between use of solid fuel and higher blood pressure ${ }^{25-28}$ or prevalence of hypertension, ${ }^{22}{ }^{29-31}$ but in others, no association was apparent. ${ }^{253233}$

In Pakistan, where biomass fuel is used for cooking and heating by $52 \%$ of households overall, and $75 \%$ in rural areas, an exploratory case-control study found an elevated risk of acute coronary syndrome among women using solid fuel. ${ }^{20}$

We, therefore, carried out a cross-sectional survey to explore the association between CHD and cooking with biomass in a sample of women drawn from the general population in rural areas of Pakistan. The objective of the study was to compare the prevalence of hypertension, angina, previous history of heart attack and ECG changes indicative of CHD in women $\geq 40$ years of age who used biomass fuel for cooking with that in women of similar age who cooked using other types of fuel.

\section{MATERIALS AND METHODS \\ Study setting}

The survey was conducted during 2015 in villages surrounding the main urban area of Nawabshah district (recently renamed as Shaheed Benazirabad) in the province of Sindh, Pakistan. These were selected to give a mix in the fuels used for cooking within the study sample. Some of the villages had been supplied with natural gas for at least 10 years, whereas in others biomass fuel (wood and/or cow dung) was still being used.

\section{Recruitment of households and subjects}

Within each village, trained field workers made door-todoor visits, and asked the heads of households whether their families would be willing to assist with the study, and if so, what type of fuel was used for cooking, and whether food preparation was regularly undertaken by a woman $\geq 40$ years of age. In this way, the study team identified quotas of the required numbers of households in each of the two categories of fuel use (biomass and other). The heads of these households were then asked to complete a consent form, and to identify and introduce the woman of the household aged $\geq 40$ years who had carried out the most cooking in the house over the last 10 years. The study was explained to her, and she was invited to participate and to give signed consent.

\section{Inclusion criteria}

Women aged 40 years or older were eligible for inclusion if they gave informed consent, and had been cooking in the household for at least the last year, using only one of biomass fuel or non-biomass fuel.

\section{Questionnaire, examination and measurements}

A standardised questionnaire was used to collect information at interview about: demographic and socioeconomic characteristics, birth weight, smoking history, whether another member of the household was a regular smoker, relevant aspects of diet, physical activity, lifetime history of cooking using different types of fuel, any previous diagnosis of a 'heart attack' by a doctor, symptoms of angina (through the Rose angina questionnaire ${ }^{34}$ ) and any current use of medication for hypertension. In addition, measurements were made of height, weight, waist circumference, hip circumference and blood pressure.

Socioeconomic status was characterised by the literacy of the participant (no vs any literacy), the type of employment of her father during her childhood (manual or non-manual), the ownership and construction of her house ('pucca', ie, made of concrete walls and roof or 'katcha/semi-pucca', ie, made fully or partially of thatched walls and roof), the income level of the household and the number of household assets owned from a list of seven. Birth weight was determined from participants' recall as being 'higher than normal versus normal versus lower than normal'.

The questions on smoking covered use of cigarettes or bidi (locally made cigarettes without filters) or a hookah (pipe) regularly (at least once a week for a month or longer). The number of other people in the household who smoked provided a measure of domestic exposure to environmental tobacco smoke (ETS), which was classified according to whether at least one other household member smoked cigarettes or bidi or a hookah in the home.

Dietary questions covered the use of oil or ghee for cooking and eating, and weekly consumption of meat and eggs. The former was categorised to three levels: only or mostly use oil; mixed use of oil and ghee; only or mostly use ghee. Frequencies of consuming meat and eggs were each categorised to two levels: at least once per week versus less than once per week.

Level of physical activity was assessed through questions on the frequency per week of shopping, fetching water, washing clothes, collecting wood for cooking, agricultural work on a farm and any other regular heavy physical work. Each of these activities was categorised to two levels: 0 days per week or at least once per week. A composite physical activity score was then derived as the number of 
activities carried out at least once per week, with values ranging from 0 to 6 .

Height, weight, and waist and hip circumference were measured using a stadiometer, digital weighing scale and measuring tape, following standardised methods. Body mass index (BMI) (weight in kilograms per squared height in metres) and waist-to-hip ratio (WHR) were then calculated from the measurements. BMIs $\geq 25 \mathrm{~kg} / \mathrm{m}^{2}$ were considered abnormally high (overweight or obese), as were WHRs of $\geq 0.85$.

\section{Categories of exposure to biomass}

Use of biomass was classed to two main categories; biomass users who currently used firewood and/or cow dung for cooking; and non-users of biomass who did not (other sorts of biomass were not used for cooking in the community studied).

In addition, two subsets of these main categories were distinguished: long-term biomass users who currently used firewood and/or cow dung for cooking and had done so for at least the last 10 years; and long-term non-users of biomass who currently did not use either firewood or cow dung for cooking and had not done so for at least the last 10 years.

\section{Outcome measures}

Four outcome measures were specified.

\section{Hypertension}

Three measurements of blood pressure were made at 5 min intervals, using an Omron upper arm blood pressure monitor, and mean values for systolic and diastolic blood pressure were derived. Women were deemed to have hypertension if they met at least one of the three criteria: mean systolic blood pressure $\geq 140 \mathrm{~mm} \mathrm{Hg}$; mean diastolic blood pressure $\geq 90 \mathrm{~mm} \mathrm{Hg}$; regular use of medication for blood pressure.

\section{Angina}

Experience of angina was assessed through the Rose angina questionnaire, ${ }^{34}$ which comprises seven questions relating to chest pain, its anatomical distribution, precipitating and relieving factors, and duration. A diagnosis of angina required report of pain, pressure or discomfort in the chest centrally, or in both the left anterior chest and left arm, that occurred when walking uphill or hurrying, that caused the participant to stop or slow down when it occurred while walking and that was then relieved within 10 min by standing still.

\section{Heart attack}

Previous diagnosis of heart attack by a doctor was ascertained through a single question: 'In the past, have you ever been told by a health care provider that you had a 'heart attack'?'

\section{Definite or probable CHD on ECG}

A 12-lead ECG was recorded according to a standard protocol, and coded for the presence of definite or probable CHD, using the Minnesota Code Manual of
Electrocardiographic Findings, second edition. ${ }^{35}$ This corresponded to the presence of any of codes 1-1 to 1-3, $3-1,4-1$ to $4-4,5-1$ to $5-3,7-1-1$ and $9-2$. In order to check the repeatability of the coding, two of us (ZF and DC) coded all of the ECGs independently. We used the same scanned ECG traces, without information about the type of cooking fuel used by the participant. Levels of agreement between the observers were assessed, using kappa statistics. Where differences occurred in the classification of an ECG trace, they were then resolved by discussion between the two observers.

\section{Statistical analysis}

Data were double entered in Epidata V.3.1 software $^{36}$ for validation. All discrepancies were corrected by reference to the original questionnaire or record sheet. Statistical analysis was carried out with Stata V.12.0. ${ }^{37}$

As a first step, several variables were reclassified or combined, based on their distribution in the full study sample, and without knowledge of participants' use of biomass fuel. Thus, a combined index was derived for frequency of consuming meat and eggs with three levels: neither meat nor eggs as much as once per week; one of meat or eggs at least once per week; both meat and eggs at least once per week. Scores for physical activity were categorised into three levels: low (0-1 activities), medium (2-3) and high (4 or more). Similarly, BMI and WHR were combined as a single variable with three categories: neither BMI nor WHR high; one of BMI or WHR high; both BMI and WHR high.

Descriptive statistics were produced for women in each of the four categories of exposure to biomass, summarising their demographic and socioeconomic characteristics, current and previous cooking arrangements, types and durations of fuel use, hours of cooking per day, types of stove and kitchen and exposures to potentially confounding risk factors. The prevalence of the main outcomes was determined for the study sample overall, and the relationship of ECG changes to angina and history of heart attack was explored.

Logistic regression analysis was then used to assess the association of each of the four outcome variables with use of biomass fuel for cooking and other possible risk factors. First, associations with each potential risk factor were determined after adjustment for age. The main exposure of interest (user or non-user of biomass) was then carried forward into a mutually adjusted model along with all other risk factors which showed associations $(p \leq 0.1)$ when examined individually. In addition, a second mutually adjusted model was fitted that compared long-term use and non-use of biomass for cooking.

\section{Sample size}

The size of the study sample was determined by a power calculation which assumed an outcome prevalence of at least $6 \%$ for definite CHD among non-users of biomass fuel, based on a previous study in Pakistan ${ }^{38}$ (the prevalence of other outcomes was expected to be higher). This 
indicated that we would require at least 876 women (438 users and 438 non-users of biomass) for $80 \%$ power to detect an OR of 2.0 for the use of biomass fuel with a $5 \%$ level of statistical significance.

\section{Patient and public involvement}

There was no involvement of patients or the public in development of this study.

\section{RESULTS}

A total of 24 villages were visited in order to recruit the number of households required for the survey. In 14 villages, all households used biomass for cooking, while in 3 all used natural gas, and in the other 7 , both types of fuel were used. The number of participating households per village ranged from as few as three to as many as 210 . Interviews were completed with women from a total of 1073 households, 536 of which currently used biomass fuel, and 537 natural gas (including liquid petroleum gas (LPG)). No-one declined to participate in the study, but 77 women could not be interviewed because they were not at home at the time when the survey team visited (mostly because they were engaged in agricultural work).
Among the 1073 women who completed interviews, 44 indicated that they were in fact aged $<40$ years of age, and were therefore excluded from the analysis. An additional 151 women had not made meals regularly (at least one meal per day on most days of the week) during the last year, and were also excluded. We further excluded 28 women who did not currently use firewood or cow dung for cooking, but whose time since last use of biomass was $<2$ years (this was done to ensure distinct exposure categories). Thus, further analysis was based on 850 women: 436 users and 414 non-users of biomass. Among them, 430 were longterm users of biomass, and 263 were long-term non- users.

Table 1 summarises the demographic and socioeconomic characteristics of the participants in the study sample overall, and according to categories of exposure to biomass fuel. In comparison with users of biomass, non-users were marginallyyounger ( $63 \%$ vs $60 \%<50$ years), and somewhat more advantaged socioeconomically.

Table 2 describes the current and previous cooking arrangements of participants, including type and duration of fuel use, intensity of cooking and type of stove and kitchen. Even among the long-term non-users of biomass, $88 \%$ had cooked with biomass fuels at some time in their

Table 1 Demographic and socioeconomic characteristics of participants by exposure category

\begin{tabular}{|c|c|c|c|c|c|}
\hline & $\begin{array}{l}\text { All women } \\
(n=850)\end{array}$ & $\begin{array}{l}\text { Users of biomass } \\
(n=436)\end{array}$ & $\begin{array}{l}\text { Non-users of } \\
\text { biomass } \\
(n=414)\end{array}$ & $\begin{array}{l}\text { Long-term users } \\
\text { of biomass } \\
(n=430)\end{array}$ & $\begin{array}{l}\text { Long-term non- } \\
\text { users of biomass } \\
(\mathrm{n}=263)\end{array}$ \\
\hline Characteristics & n (\%) & n (\%) & $\mathrm{n}(\%)$ & n (\%) & n (\%) \\
\hline \multicolumn{6}{|l|}{ Age (years) } \\
\hline$<50$ & $525(61.8)$ & $263(60.3)$ & 262 (63.3) & $257(59.8)$ & $166(63.1)$ \\
\hline$\geq 50$ & 325 (38.2) & $173(39.7)$ & $152(36.7)$ & $173(40.2)$ & 97 (36.9) \\
\hline \multicolumn{6}{|l|}{ Educational status } \\
\hline No literacy & 797 (93.8) & $419(96.1)$ & 378 (91.3) & $413(96.1)$ & 239 (90.9) \\
\hline Any literacy & $53(6.2)$ & $17(3.9)$ & $36(8.7)$ & $17(4.0)$ & $24(9.1)$ \\
\hline \multicolumn{6}{|c|}{ Household income/month } \\
\hline$\leq 10000$ PKR & $651(76.6)$ & $351(80.5)$ & $300(72.5)$ & $347(80.7)$ & $185(70.3)$ \\
\hline >10 000 PKR & $199(23.4)$ & 85 (19.5) & $114(27.5)$ & 83 (19.3) & $78(29.7)$ \\
\hline \multicolumn{6}{|l|}{ Household tenure } \\
\hline Rented & $70(8.2)$ & $25(5.7)$ & 45 (10.9) & $25(5.8)$ & $20(7.6)$ \\
\hline Owned & $780(91.8)$ & $411(94.3)$ & $369(89.1)$ & $405(94.2)$ & $243(92.4)$ \\
\hline \multicolumn{6}{|l|}{ Construction of house } \\
\hline Katcha/semi-pucca & $652(76.7)$ & $361(82.8)$ & $291(70.3)$ & $356(82.8)$ & $173(65.8)$ \\
\hline Pucca & $198(23.3)$ & $75(17.2)$ & $123(29.7)$ & $74(17.2)$ & $90(34.2)$ \\
\hline \multicolumn{6}{|l|}{ No of household assets } \\
\hline Low (0-1) & $268(31.5)$ & $140(32.1)$ & $128(30.9)$ & 139 (32.3) & 84 (31.9) \\
\hline Medium (2-3) & $404(47.5)$ & $223(51.2)$ & $181(43.7)$ & $218(50.7)$ & $108(41.1)$ \\
\hline High $(\geq 4)$ & $178(21.0)$ & $73(16.7)$ & $105(25.4)$ & $73(17.0)$ & $71(27.0)$ \\
\hline \multicolumn{6}{|c|}{ Father's occupation in childhood } \\
\hline Non-manual & $39(4.6)$ & $19(4.4)$ & $20(4.8)$ & $18(4.2)$ & $16(6.1)$ \\
\hline Manual & $811(95.4)$ & $417(95.6)$ & $394(95.2)$ & $412(95.8)$ & 247 (93.9) \\
\hline
\end{tabular}


Table 2 Current and previous cooking arrangements according to exposure category

\begin{tabular}{|c|c|c|c|c|}
\hline & $\begin{array}{l}\text { Users of biomass } \\
(n=436)\end{array}$ & $\begin{array}{l}\text { Non-users of } \\
\text { biomass }(n=414)\end{array}$ & $\begin{array}{l}\text { Long-term users of } \\
\text { biomass }(n=430)\end{array}$ & $\begin{array}{l}\text { Long-term non-users } \\
\text { of biomass ( } n=263 \text { ) }\end{array}$ \\
\hline Characteristics & $\mathrm{n}(\%)$ & n (\%) & n (\%) & n (\%) \\
\hline Ever used biomass for cooking & $436(100)$ & $382(92.3)$ & $430(100)$ & $231(87.8)$ \\
\hline \multicolumn{5}{|c|}{ Years since last used biomass for cooking } \\
\hline Current user & $436(100)$ & - & $430(100)$ & - \\
\hline $2-9$ & - & $151(39.5)$ & - & - \\
\hline$\geq 10$ & - & $231(60.5)$ & - & $231(100)$ \\
\hline Ever used wood for cooking & $435(99.8)$ & $358(86.5)$ & $429(99.8)$ & $218(82.9)$ \\
\hline Ever used cow dung for cooking & $422(96.8)$ & $358(86.5)$ & $416(96.7)$ & $216(82.1)$ \\
\hline Ever used kerosene for cooking & $16(3.7)$ & $26(6.3)$ & $16(3.7)$ & $17(6.5)$ \\
\hline $\begin{array}{l}\text { Ever used LPG/natural gas for } \\
\text { cooking }\end{array}$ & $17(3.9)$ & $413(99.8)$ & $15(3.5)$ & $263(100)$ \\
\hline \multicolumn{5}{|c|}{ Average hours per day cooked in last year } \\
\hline$\leq 1$ & $129(29.6)$ & $133(32.1)$ & $123(28.6)$ & $75(28.5)$ \\
\hline $2-3$ & $270(61.9)$ & $237(57.3)$ & $270(62.8)$ & $165(62.7)$ \\
\hline$\geq 4$ & $37(8.5)$ & $44(10.6)$ & $37(8.6)$ & $23(8.8)$ \\
\hline \multicolumn{5}{|l|}{ Type of stove used for cooking } \\
\hline Gas/LPG & $2(0.5)$ & $414(100)$ & $2(0.5)$ & $263(100)$ \\
\hline $\begin{array}{l}\text { Biomass with chimney/ } \\
\text { improved stove }\end{array}$ & $166(38.1)$ & - & $164(38.1)$ & - \\
\hline $\begin{array}{l}\text { Biomass with three brick open } \\
\text { stove }\end{array}$ & 267 (61.2) & - & $263(61.2)$ & - \\
\hline Other & $1(0.2)$ & - & $1(0.2)$ & - \\
\hline \multicolumn{5}{|l|}{ Type of kitchen } \\
\hline $\begin{array}{l}\text { Closed (four walls-linked with } \\
\text { living room or separate) }\end{array}$ & $88(20.2)$ & $116(28.0)$ & $86(20.0)$ & $79(30.0)$ \\
\hline $\begin{array}{l}\text { Semi-open (fewer than four } \\
\text { walls) }\end{array}$ & $189(43.3)$ & $155(37.4)$ & $187(43.5)$ & $94(35.7)$ \\
\hline Open (no walls) & $159(36.5)$ & $143(34.5)$ & $157(36.5)$ & $90(34.2)$ \\
\hline Heat home with biomass & $237(54.4)$ & $106(25.6)$ & $236(54.9)$ & $74(28.1)$ \\
\hline
\end{tabular}

life. Among the biomass users, the large majority had used wood $(93 \%)$ and cow dung $(88 \%)$ for longer than 20 years. Few participants $(3.7 \%$ of biomass users and $6.3 \%$ of non-users) had ever used kerosene as a cooking fuel. Most participants $(\sim 60 \%)$ currently cooked for $2-3$ hours per day, the average duration of cooking per day being similar in users and non-users of biomass. Where biomass was used for cooking, it was also more likely to be used to heat the home.

Table 3 shows the distribution of potentially confounding risk factors for CHD in the four categories of exposure to biomass. In comparison with non-users of biomass, slightly higher proportions of women using biomass reported having been born with 'lower than normal' birth weight, having lost weight at some time during childhood, ever having smoked and being exposed to ETS in the home.

\section{Prevalence of outcome measures}

Online supplementary table 1 shows the prevalence of the main outcome measures that were investigated. In total,
297 women $(35 \%)$ were classed as having hypertension, two-thirds of whom were taking regular medication for blood pressure. About 27\% had symptoms indicative of angina based on Rose's questionnaire. Fifty-four (6.4\%) reported a previous history of heart attack, and $19 \%$ of women had findings of 'definite or probable CHD on ECG'.

\section{Validity of ECG classification and interrelationships of} outcome measures

Online supplementary table 2 compares the classification of ECGs by the two observers. Satisfactory ECG traces were obtained for $841(98.9 \%)$ of the participants, but 4 were missing from the file used to assess interobserver agreement, and were later assessed jointly by the two observers. The overall agreement between the two observers was $85.2 \%$ $(\mathrm{kappa}=0.57)$. Most disagreements were related to cases in which the exceedance of a threshold in, for example, ST elevation, ST depression or the width (duration) of a Q wave was borderline. In some cases, it was questionable whether 
Table 3 Distribution of risk factors across the four exposure categories

\begin{tabular}{|c|c|c|c|c|}
\hline & $\begin{array}{l}\text { Users of biomass } \\
(n=436)\end{array}$ & $\begin{array}{l}\text { Non-users of } \\
\text { biomass }(n=414)\end{array}$ & $\begin{array}{l}\text { Long-term users of } \\
\text { biomass }(n=430)\end{array}$ & $\begin{array}{l}\text { Long-term non-users } \\
\text { of biomass }(n=263)\end{array}$ \\
\hline Characteristics & n (\%) & n (\%) & n (\%) & n (\%) \\
\hline \multicolumn{5}{|l|}{ Birth weight } \\
\hline Lower than normal & $117(26.8)$ & $77(18.6)$ & $114(26.5)$ & $54(20.5)$ \\
\hline Normal & $239(54.8)$ & $254(61.4)$ & $237(55.1)$ & $156(59.3)$ \\
\hline Higher than normal & $80(18.4)$ & $83(20.0)$ & $79(18.4)$ & $53(20.2)$ \\
\hline \multicolumn{5}{|c|}{ Ever hungry all the time during childhood because there was not enough food } \\
\hline No & $176(40.4)$ & $176(42.5)$ & $175(40.7)$ & $122(46.4)$ \\
\hline Yes & $260(59.6)$ & $238(57.5)$ & $255(59.3)$ & $141(53.6)$ \\
\hline \multicolumn{5}{|c|}{ Lost weight during childhood } \\
\hline No & $162(37.2)$ & $182(44.0)$ & $160(37.2)$ & $119(45.2)$ \\
\hline Yes & $274(62.8)$ & $232(56.0)$ & $270(62.8)$ & $144(54.8)$ \\
\hline \multicolumn{5}{|c|}{ Ever smoked regularly (any of cigarettes, bidi, huqqa) } \\
\hline Never & $390(89.4)$ & $378(91.3)$ & 384 (89.3) & 240 (91.3) \\
\hline Ever & $46(10.6)$ & $36(8.7)$ & $46(10.7)$ & $23(8.7)$ \\
\hline
\end{tabular}

Environmental tobacco smoke (at least one other household member smoked cigarettes, bidi or huqqa in the home)

\begin{tabular}{|c|c|c|c|c|}
\hline No & $269(61.7)$ & $267(64.5)$ & $265(61.6)$ & $173(65.8)$ \\
\hline Yes & 167 (38.3) & $147(35.5)$ & $165(38.4)$ & $90(34.2)$ \\
\hline \multicolumn{5}{|l|}{ Physical activity score } \\
\hline $0-2$ & $124(28.4)$ & 205 (49.5) & $124(28.8)$ & $149(56.7)$ \\
\hline $3-4$ & $199(45.6)$ & $156(37.7)$ & $196(45.6)$ & $91(34.6)$ \\
\hline $5-6$ & $113(25.9)$ & $53(12.8)$ & $110(25.6)$ & $23(8.7)$ \\
\hline \multicolumn{5}{|c|}{ Consumption of meat or eggs } \\
\hline $\begin{array}{l}\text { Do not eat either meat or } \\
\text { eggs as much as once per } \\
\text { week }\end{array}$ & $173(39.7)$ & $142(34.3)$ & $172(40.0)$ & $88(33.5)$ \\
\hline $\begin{array}{l}\text { Eat one of meat or eggs } \\
\text { as much as once per } \\
\text { week }\end{array}$ & $176(40.4)$ & $163(39.4)$ & $173(40.2)$ & $100(38.0)$ \\
\hline $\begin{array}{l}\text { Eat both meat and eggs at } \\
\text { least once per week }\end{array}$ & $87(20.0)$ & $109(26.3)$ & $85(19.8)$ & $75(28.5)$ \\
\hline \multicolumn{5}{|l|}{ Current nutrition* } \\
\hline Neither BMI nor WHR high & $183(42.0)$ & $129(31.2)$ & $179(41.6)$ & $79(30.0)$ \\
\hline One of BMI or WHR high & $151(34.6)$ & $160(38.7)$ & $149(34.7)$ & $101(38.4)$ \\
\hline Both BMI and WHR high & $102(23.4)$ & $124(30.0)$ & $102(23.7)$ & $82(31.2)$ \\
\hline Not known & $0(0)$ & $1(0.2)$ & $0(0)$ & $1(0.4)$ \\
\hline
\end{tabular}

${ }^{*} \mathrm{BMI}\left(\mathrm{kg} / \mathrm{m}^{2}\right) \geq 25=$ high; WHR $\geq 0.85=$ high.

$\mathrm{BMI}$, body mass index; WHR, waist-to-hip ratio.

there was a small $\mathrm{R}$ wave or a QS pattern. Also, there was some disagreement about whether $\mathrm{T}$ waves were negative or flat. Following discussion between the two observers, all of the discrepancies were reconciled, and it was finally agreed that 181 women $(21.5 \%)$ showed changes indicative of 'definite or probable CHD'. However, in 22 of these cases, it appeared that the abnormality had occurred only because the ECG leads had been placed incorrectly, and those traces were reclassified as normal. Thus in further analyses, 159
(19\%) of women were considered to have definite or probable CHD on ECG.

Online supplementary table 3 shows the prevalence of definite or probable CHD on ECG according to symptoms of angina and history of heart attack. It was somewhat more frequent in participants who reported an earlier heart attack (26\%) than in those who did not and had no symptoms of angina (18\%). However, there was no association with angina in the absence of heart attack. 
Table 4 Associations of hypertension, angina, history of heart attack and definite or probable CHD on ECG with current and long-term use of biomass for cooking

\begin{tabular}{|c|c|c|c|}
\hline & Adjusted only for age $(n=850)^{\star}$ & Fully adjusted*(n=850) & biomass† (n=693) \\
\hline Outcome & OR (95\% Cl) & OR $(95 \% \mathrm{Cl})$ & OR (95\% Cl) \\
\hline \multicolumn{4}{|l|}{ Hypertension } \\
\hline Non-users of biomass & 1.0 & 1.0 & 1.0 \\
\hline Users of biomass & $1.2(0.9$ to 1.5$)$ & $1.0(0.8$ to 1.4$)$ & $1.1(0.8$ to 1.6$)$ \\
\hline \multicolumn{4}{|l|}{ Angina } \\
\hline Non-users of biomass & 1.0 & 1.0 & 1.0 \\
\hline Users of biomass & $1.0(0.7$ to 1.3$)$ & $1.0(0.8$ to 1.4$)$ & $1.3(0.9$ to 1.9$)$ \\
\hline \multicolumn{4}{|l|}{ Heart attack } \\
\hline Non-users of biomass & 1.0 & 1.0 & 1.0 \\
\hline Users of biomass & 1.4 (0.8 to 2.4$)$ & 1.2 (0.7 to 2.2$)$ & 1.3 (0.7 to 2.4$)$ \\
\hline \multicolumn{4}{|c|}{ Definite or probable CHD on ECG } \\
\hline Non-users of biomass & 1.0 & 1.0 & 1.0 \\
\hline Users of biomass user & 0.8 (0.6 to 1.2$)$ & 0.8 (0.6 to 1.2$)$ & 0.9 (0.6 to 1.3$)$ \\
\hline
\end{tabular}

*Mutually adjusted risk estimates derived from a single regression model that included use of biomass and all of the variables that were significant $(p<0.1)$ in analyses adjusted only for age.

†Mutually adjusted risk estimates derived from a single regression model that included use of biomass and all of the variables that were significant $(p<0.1)$ in analyses adjusted only for age, but was restricted to women who were long-term users or non-users of biomass. $\mathrm{CHD}$, coronary heart disease.

\section{Association of outcome measures with use of biomass and other risk factors}

Associations of hypertension and the three CHD outcomes (angina, heart attack and definite or probable CHD on ECG) with potential risk factors are presented in online supplementary table 4-7, from which the risk estimates for use of biomass fuel for cooking are summarised in table 4. The first column of each table gives ORs adjusted only for age, while the second column presents mutually adjusted risk estimates from a single model that included use of biomass and all of the risk factors that showed associations $(p \leq 0.1)$ in the analyses adjusted only for age. The last column shows findings from a similar analysis but restricted to women who were long-term users or non-users of biomass.

In analyses that adjusted only for age, hypertension was associated $(p \leq 0.1)$ with older age, a higher number of household assets, higher frequency of consuming meat and eggs, and having a high BMI or WHR (online supplementary table 4 ). When these variables were carried forward to the mutually adjusted analysis, the association with consumption of meat and eggs was diminished, but the others remained. Thus, the risk of hypertension increased $40 \%$ with every 10-year increase in age, was 2.3 times higher in women with $\geq 4$ household assets than in those with 0 or 1 , and was increased 1.9-fold in women who had both high BMI and high WHR as compared with those in whom neither BMI nor WHR were elevated. However, hypertension was not associated with use of biomass (OR 1.0 in the fully adjusted model). When analysis was restricted to long-term users and non-users of biomass, results were similar, with an OR of 1.1 for longterm use of biomass.

In analyses that adjusted only for age, the odds of angina increased with age and regular smoking, and were significantly lower with more frequent consumption of meat and eggs (online supplementary table 5). Moreover, this pattern was maintained when risk estimates were mutually adjusted. Thus, the odds of angina increased by $30 \%$ per 10 -year increase in age, and with ever having smoked regularly (OR 2.0, 95\% CI 1.2 to 3.2 ), and were significantly lower in women who ate both meat and eggs at least once per week (OR $0.5,95 \%$ CI 0.3 to 0.7$)$. There was, however, no association with use of biomass (OR 1.0, 95\% CI 0.8 to 1.4). When analysis was restricted to long-term users and non-users of biomass, results were similar except that there was a suggestion of a weak association with exposure to biomass (OR 1.3, $95 \%$ CI 0.9 to 1.9 ).

In corresponding analyses with previous history of heart attack (diagnosed by a physician) as an outcome, initial models with adjustment only for age indicated associations $(\mathrm{p}<0.1)$ with age, higher household income, higher number of household assets and high BMI or WHR (online supplementary table 6). After mutual adjustment, age remained a significant risk factor (OR 1.5, 95\% CI 1.2 to 2.0, for each 10-year increase in age). However, the other associations, although still positive, were not significant at a 5\% level. Nor was there an association with use of biomass for cooking (OR 1.2, $95 \%$ CI 0.7 to 2.2). In the 
mutually adjusted model for long-term use of biomass, results were very similar.

In analyses adjusted only for age, household income was the only variable significantly associated with definite or probable CHD on ECG, and it remained significant in the fully adjusted model (OR 1.6, 95\% CI 1.1 to 2.4 for household income $>10000 \mathrm{PKR}$ ) (online supplementary table 7). However, there was no association with use of biomass for cooking, either overall or in the long-term (ORs 0.8 and 0.9).

\section{DISCUSSION}

This study found no association between use of biomass fuel and any of the four outcomes studied (hypertension, angina, previous history of heart attack and definite or probable CHD on ECG), even when comparison was with women who had not used biomass for at least the last 10 years. The strongest hint of an association was for angina in long-term users as compared with long-term non-users of biomass, but the elevation of risk was small $(30 \%)$ and not statistically significant at a $5 \%$ level.

The choice of villages from which to recruit participants ensured a balance in the fuels currently used for cooking, and cooperation in the survey was good with high response rates from the households and women who were invited to take part. Inevitably, recruitment was to some extent opportunistic and limited to one province of Pakistan. However, there seems no reason to expect that the study sample would have been seriously unrepresentative in the associations of hypertension and CHD with use of biomass and other risk factors.

A linked air monitoring study found that in the kitchens of houses using biomass for cooking, the mean 24 hours $\mathrm{PM}_{2.5}$ concentration was $531 \mu \mathrm{g} / \mathrm{m}^{3}$, with a median of 136 $\mu \mathrm{g} / \mathrm{m}^{3}$ and interquartile range $34-615 \mu \mathrm{g} / \mathrm{m}^{3}$ (paper in preparation). Corresponding concentrations in houses not using biomass for cooking were 69.9, 24.2 and 13.5$53.3 \mathrm{\mu g} / \mathrm{m}^{3}$. Thus, while individual exposures may have been influenced also by time spent cooking and whether biomass was burned in a closed or open kitchen, the absence of associations with CHD and hypertension is unlikely to reflect inadequate contrasts in recent intensity of exposure.

Our aim was as far as possible to recruit households that had used the same fuel for cooking exclusively for at least last 10 years. Villages were selected with this criterion in mind, and it was covered in preliminary inquiries that were addressed to local community representatives. In practice, however, it turned out that where natural gas was available in villages, some participants had not yet switched to cleaner fuel, or had done so at a later date than others. A pragmatic decision was therefore made to include women even if they had changed their cooking fuel within the last 10 years, provided that they had used their current fuel for at least a year. This seemed reasonable since trials had suggested that interventions to reduce HAP from use of biomass for cooking can produce reductions in blood pressure and changes in ECGs over the short to medium term. ${ }^{39-41}$ However, to check that it did not obscure associations, additional analyses were carried out with restriction to long-term users and non-users of biomass, and still no relationship was found with the health outcomes.

The sample size achieved for the study was close to that planned, and the prevalence of the four outcomes was higher than had been assumed in the power calculations. Moreover, the upper confidence limits for the ORs relating to use of biomass were almost all $<2$. Thus, the absence of associations with biomass does not reflect a lack of statistical power.

Ascertainment of current use of biomass is likely to have been highly accurate, and while there may have been some errors in recall of the times when biomass had been used in the past, it is difficult to conceive that any resultant misclassification would have obscured important associations with CHD. Generally, switches in the use of fuel were only in one direction-towards cleaner natural gas from biomass. The timing of changes was usually well recalled because in most instances the entire village received the new source of fuel in a particular year. However, the duration of using cow dung and firewood may not always have been remembered reliably, and switches between these types of fuel could also have occurred. Many women reported using cow dung and firewood for the same duration, and no attempt was made to analyse them separately.

Recall of some potentially confounding exposures may also have been inaccurate-particularly those pertaining to childhood. If so, the errors would be expected to be non-differential with respect to CHD, and therefore to bias risk estimates towards the null, possibly leading to uncontrolled residual confounding. However, the assessment of BMI and WHR used standardised methods, and should have been reasonably reliable. The interviewers were trained in how to make the measurements, and their technique was piloted in the field before the start of data collection.

A greater concern is the possibility of error in the ascertainment of outcomes. Blood pressure was objectively measured according to a standardised protocol, and was taken as the average of three readings. Moreover, most of the women who were classed as having hypertension were taking treatment for the disorder, which supports the validity of its assessment. Angina was determined through the well-established Rose questionnaire, but it is possible that symptoms in some cases arose from other pathology. Previous research has suggested that the Rose angina questionnaire may not be as reliable among women as in men. ${ }^{42}$ Although the question to participants about history of heart attack referred specifically to diagnoses that had been given by a health professional, errors could have occurred in interpretation of the term heart attack (eg, to include symptoms from dysrhythmias and acute heart failure as well as myocardial infarction). However, ascertainment of heart attack had been previously carried out by the same method in a 
similar population, where it was found to be reasonably accurate. ${ }^{43}$

The diagnosis of CHD from ECGs showed only a weak relationship to history of medically diagnosed heart attack, and none at all to symptoms of angina (online supplementary table 3). Between observer agreement in the classification of ECGs was reasonably good (kappa $=0.57$ ) (online supplementary table 2), but it is notable that unlike angina and history of heart attack, CHD diagnosed from ECGs did not show the expected association with age (online supplementary table 7 ).

To the extent that errors did occur in the ascertainment of outcomes, they are unlikely to have differed systematically in relation to use of biomass, and therefore would be expected to tend to obscure any true associations.

Because the study had a cross-sectional design, consideration must be given to the possibility of reverse causation. For risk factors related to childhood (eg, birth weight, father's occupation and education), this is less of a concern. However, it is plausible that characteristics such as diet, physical activity and time spent cooking could have changed as a consequence of CHD. Depending on the circumstances, this might bias associations either upwards or downwards.

Another limitation of the study was that it did not determine when previous heart attacks had occurred. Even if not as a consequence of an earlier heart attack, some of the exposures studied (eg, BMI and WHR) may have changed in the interval since such an attack occurred. If so, this might obscure true associations.

A further possible source of error was uncontrolled residual confounding. To minimise this problem, information was collected about a range of potentially confounding variables, and as in most studies of biomass fuel, socioeconomic status tended to be higher in women using cleaner fuels. ${ }^{44}$ Although several socioeconomic indicators were evaluated as possible factors for adjustment, residual confounding could still have occurred. To explain the absence of associations with biomass, such confounding would have to be inverse (ie, the under-ascertained confounder would have to be less prevalent in women who used biomass than in non-users).

The study found expected associations with several established risk factors for CHD. Thus, the odds of hypertension, angina and previous history of heart attack were all higher with older age (by $30 \%-50 \%$ for every 10-year increase), although this was not found for definite or probable CHD on ECG. The relationship of CHD to age is well documented in the literature, ${ }^{45}$ and in women, the incidence of CHD increases rapidly after the menopause, reaching up to three times that in premenopausal women. ${ }^{46}$

Two of the outcome measures-hypertension and previous history of heart attack-were significantly associated with affluence as measured by number of household assets. This relationship has also been observed before. In a population-based study in Pakistan, history of 'angina or heart attack' was estimated to have threefold higher prevalence among affluent participants than in those who were poor. ${ }^{47}$ The direction of the association, which is the inverse of that observed in western populations, accords with a higher prevalence of diabetes, hypertension and dyslipidaemias in more educated and affluent groups, which was found in a recent study conducted in South Asian countries, including Pakistan. ${ }^{48}$

In further support of an effect of affluence, we found that high BMI and/or WHR was associated with greater risk of hypertension, and (non-significantly) with history of heart attack. Obesity has been shown to increase the risk of hypertension in several studies, ${ }^{4950}$ and partly through this mechanism, also increases the risk and progression of CHD. ${ }^{51}$ The INTERHEART study suggested that WHR (abdominal obesity) is a better marker of risk for CHD than BMI, ${ }^{52}$ but the two were correlated in our study sample, and we opted to use a combined measure.

In contrast, we found that more frequent consumption of meat and eggs was associated with reduced risk of angina. This was unexpected given the known relationship of CHD to consumption of saturated fat, ${ }^{53}$ and may have been a chance finding. It did not extend to the other outcomes investigated. However, a recent large global review of the literature on saturated fats suggests that this relationship may be inconsistent. ${ }^{54}$

Smoking has consistently been found to increase the risk of CHD in many studies. ${ }^{55}$ However, in our investigation, it was associated only with angina. This might be because intensity of tobacco use among female smokers in the Pakistani population is low. ${ }^{56}$

Despite the finding of several expected associations, the failure to demonstrate more consistent relationships to known risk factors is a further indication for caution in the interpretation of our results.

Several earlier studies have indicated links between use of biomass for cooking and CHD, although the finding has not been entirely consistent. ${ }^{1718}$ As already discussed, one explanation for our failure to demonstrate such associations in the current study could be inaccuracies in the diagnosis of CHD. Another possibility, however, is that adverse effects of exposure to pollutants from the use of biomass persist many years after last exposure. In this survey, even among women who had not used biomass during the last 10 years, most had done so earlier, and often for a long time. Only a few participants (about 3.5\% overall) had never used biomass, which was too few for meaningful risk estimates. While it would be possible to compare rural users of biomass with lifelong users of cleaner fuels in urban settings, interpretation would be complicated by other important differences between those living in rural and urban areas.

\section{CONCLUSIONS}

This study evaluated the association of hypertension and three measures of CHD—angina, previous history of heart attack and definite or probable CHD on ECG-with use of biomass for cooking. We found no clear associations 
with any of the health outcomes. However, the weak relationship of ECG abnormalities to the other two measures of CHD, and the inconsistency of their associations with well-established risk factors, suggest that this could have been because of diagnostic misclassification. Alternatively, it could be that an effect was missed because most of the women who were not currently using biomass for cooking had used it in the past, and risk remains elevated for many years after last exposure.

Acknowledgements The study reported in this paper formed part of a $\mathrm{PhD}$ project carried out by Dr Zafar Fatmi under the supervision of Professor David Coggon at the University of Southampton, UK. Mr Syed Nayab Ali Shah coordinated the data collection. Ms Shereen Jamali, Ms Fozia Jamali, Ms Iqra Memon and Ms Sana Memon administered the questionnaires at interview and recorded the ECGs. We are grateful also to Professor Keith Palmer and Professor M. Masood Kadir for their advice on various aspects of the study.

Contributors ZF led the design and conduct of the study, carried out the initial statistical analyses and wrote the first draft of the manuscript. GN oversaw and guided the statistical analysis. DC supervised the project and amended the first draft of the manuscript. All authors approved the final version of the manuscript.

Funding This research was supported by a fellowship from the Colt Foundation for the conduct of a PhD by Professor Zafar Fatmi. Professor David Coggon and $\mathrm{Dr}$ Georgia Ntani were supported by funding from the UK Medical Research Council (MRC MC UU 12011/5).ax

Competing interests None declared.

Patient consent for publication Not required.

Ethics approval The study was approved by Ethics Review Committee of Aga Khan University, Karachi, Pakistan.

Provenance and peer review Not commissioned; externally peer reviewed.

Data availability statement Data are available upon reasonable request.

Open access This is an open access article distributed in accordance with the Creative Commons Attribution Non Commercial (CC BY-NC 4.0) license, which permits others to distribute, remix, adapt, build upon this work non-commercially, and license their derivative works on different terms, provided the original work is properly cited, appropriate credit is given, any changes made indicated, and the use is non-commercial. See: http://creativecommons.org/licenses/by-nc/4.0/.

\section{REFERENCES}

1. Bonjour S, Adair-Rohani H, Wolf J, et al. Solid fuel use for household cooking: country and regional estimates for 1980-2010. Environ Health Perspect 2013;121:784-90.

2. World Health Organization. Household air pollution and health. Geneva, Switzerland. Available: http://www.who.int/mediacentre/ factsheets/fs292/en/ [Accessed on 4 Apr 2018].

3. World Health Organization. Ambient (outdoor) air quality and health [Internet]. Geneva, 2018. Available: https://www.who.int/newsroom/fact-sheets/detail/ambient-(outdoor)-air-quality-and-health [Accessed updated 2 May 2018].

4. Naeher LP, Brauer M, Lipsett M, et al. Woodsmoke health effects: a review. Inhal Toxicol 2007;19:67-106.

5. Clark ML, Peel JL, Balakrishnan K, et al. Health and household air pollution from solid fuel use: the need for improved exposure assessment. Environ Health Perspect 2013;121:1120-8.

6. Smith KR, Samet JM, Romieu I, et al. Indoor air pollution in developing countries and acute lower respiratory infections in children. Thorax 2000;55:518-32.

7. Smith KR, Mehta S, Maeusezahl-Feuz M. Indoor air pollution from household use of solid fuels: comparative quantification of health risks. In: Ezzati MLA, Rodgers A, Murray CJL, eds. Global and regional burden of disease attributable to selected major risk factors. Geneva, Switzerland: World Health Organization, 2004: 1435-93.

8. Torres-Duque C, Maldonado D, Pérez-Padilla R, et al. Forum of international respiratory studies (FIRS) Task force on health effects of biomass exposure. biomass fuels and respiratory diseases: a review of the evidence. Proc Am Thorac Soc 2008;5:577-90.
9. Liu Y, Lee K, Perez-Padilla R, et al. Outdoor and indoor air pollution and COPD-related diseases in high- and low-income countries. Int $J$ Tuberc Lung Dis 2008;12:115-27.

10. Kurmi OP, Semple S, Simkhada P, et al. Copd and chronic bronchitis risk of indoor air pollution from solid fuel: a systematic review and meta-analysis. Thorax 2010;65:221-8.

11. Liu Q, Sasco AJ, Riboli E, et al. Indoor air pollution and lung cancer in Guangzhou, people's Republic of China. Am J Epidemiol 1993;137:145-54.

12. Kleinerman $\mathrm{R}$, Wang Z, Lubin J, et al. Lung cancer and indoor air pollution in rural China. Ann Epidemiol 2000;10:469.

13. Behera $D$, Balamugesh $T$. Indoor air pollution as a risk factor for lung cancer in women. J Assoc Physicians India 2005;53:190-2.

14. Amegah AK, Quansah R, Jaakkola JJK. Household air pollution from solid fuel use and risk of adverse pregnancy outcomes: a systematic review and meta-analysis of the empirical evidence. PLoS One 2014;9:e113920.

15. Lamichhane DK, Leem J-H, Lee J-Y, et al. A meta-analysis of exposure to particulate matter and adverse birth outcomes. Environ Health Toxicol 2015;30:e2015011.

16. Calderón-Garcidueñas L, Torres-Jardón R, Kulesza RJ, et al. Air pollution and detrimental effects on children's brain. The need for a multidisciplinary approach to the issue complexity and challenges. Front Hum Neurosci 2014;8:613.

17. Fatmi Z, Coggon D. Coronary heart disease and household air pollution from use of solid fuel: a systematic review. Br Med Bull 2016;118:91-109.

18. Yu K, Qiu G, Chan K-H, et al. Association of solid fuel use with risk of cardiovascular and all-cause mortality in rural China. JAMA 2018;319:1351-61.

19. Sathiakumar N. Indoor air pollution due to biomass fuel use and acute coronary syndrome among Sri Lankan women. Epidemiology 2012;23.

20. Fatmi Z, Coggon D, Kazi A, et al. Solid fuel use is a major risk factor for acute coronary syndromes among rural women: a matched case control study. Public Health 2014;128:77-82.

21. Kim C, Shu X-O, Hosgood HD, et al. Past use of coal for cooking is associated with all-cause mortality in the prospective Shanghai women's health study. Cancer Res 2014;74.

22. Lee M-S, Hang J-qing, Zhang F-ying, et al. In-Home solid fuel use and cardiovascular disease: a cross-sectional analysis of the Shanghai Putuo study. Environ Health 2012;11.

23. Mitter SS, Islami F, Pourshams A, et al. Use of biomass fuels for cooking and heating is associated with increased noncommunicable disease mortality: Golestan cohort study. Circulation 2012;125:AP042.

24. Alam DS, Chowdhury MAH, Siddiquee AT, et al. Adult cardiopulmonary mortality and indoor air pollution: a 10-year retrospective cohort study in a low-income rural setting. Glob Heart 2012;7:215-21.

25. Baumgartner J, Schauer JJ, Ezzati M, et al. Indoor air pollution and blood pressure in adult women living in rural China. Environ Health Perspect 2011;119:1390-5.

26. Painschab MS, Davila-Roman VG, Gilman RH, et al. Chronic exposure to biomass fuel is associated with increased carotid artery intima-media thickness and a higher prevalence of atherosclerotic plaque. Heart 2013;99:984-91.

27. Burroughs Peña M, Romero KM, Velazquez EJ, et al. Relationship between daily exposure to biomass fuel smoke and blood pressure in high-altitude Peru. Hypertension 2015;65:1134-40.

28. Neupane M, Basnyat B, Fischer R, et al. Sustained use of biogas fuel and blood pressure among women in rural Nepal. Environ Res 2015;136:343-51.

29. Ray MR, Mukherjee S, Roychoudhury S, et al. Platelet activation, upregulation of CD11b/CD18 expression on leukocytes and increase in circulating leukocyte-platelet aggregates in Indian women chronically exposed to biomass smoke. Hum Exp Toxicol 2006;25:627-35.

30. Dutta A, Mukherjee B, Das D, et al. Hypertension with elevated levels of oxidized low-density lipoprotein and anticardiolipin antibody in the circulation of premenopausal Indian women chronically exposed to biomass smoke during cooking. Indoor Air 2011;21:165-76.

31. Dutta A, Ray MR, Banerjee A. Systemic inflammatory changes and increased oxidative stress in rural Indian women cooking with biomass fuels. Toxicol Appl Pharmacol 2012;261:255-62.

32. Davutoglu V, Zengin S, Sari I, et al. Chronic carbon monoxide exposure is associated with the increases in carotid intimamedia thickness and C-reactive protein level. Tohoku J Exp Med 2009;219:201-6.

33. Clark ML, Bazemore $\mathrm{H}$, Reynolds SJ, et al. A baseline evaluation of traditional Cook stove smoke exposures and indicators of 
cardiovascular and respiratory health among Nicaraguan women. Int J Occup Environ Health 2011;17:113-21.

34. Rose G, McCartney P, Reid DD. Self-Administration of a questionnaire on chest pain and intermittent claudication. Journal of Epidemiology \& Community Health 1977;31:42-8.

35. Prineas RJ, Crow RS, Z-h Z. The Minnesota code manual of electrocardiographic findings. 2nd Edition. London: Springer London, 2010.

36. Christiansen TB, Lauritsen JM. Epidata - comprehensive data management and basic statistical analysis system. Odense denmark, epidata association, 2010. Available: http://www.epidata.dk

37. Stata Corp LP. Stata statistical software: release 12.0. USA: College Station TX, 2012

38. Jafar TH, Qadri Z, Chaturvedi N. Coronary artery disease epidemic in Pakistan: more electrocardiographic evidence of ischaemia in women than in men. Heart 2008;94:408-13.

39. McCracken J, Smith KR, Stone P, et al. Intervention to lower household wood smoke exposure in Guatemala reduces STsegment depression on electrocardiograms. Environ Health Perspect 2011;119:1562-8.

40. McCracken JP, Smith KR, Díaz A, et al. Chimney stove intervention to reduce long-term wood smoke exposure lowers blood pressure among Guatemalan women. Environ Health Perspect 2007;115:996-1001.

41. Alexander D, Larson T, Bolton S, et al. Systolic blood pressure changes in Indigenous Bolivian women associated with an improved cookstove intervention. Air Qual Atmos Health 2015;8:47-53.

42. Wilcosky T, Harris R, Weissfeld L. The prevalence and correlates of rose questionnaire angina among women and men in the lipid research clinics program prevalence study population. $\mathrm{Am} \mathrm{J}$ Epidemiol 1987;125:400-9.

43. Jafar TH, Jafary FH, Jessani $\mathrm{S}$, et al. Heart disease epidemic in Pakistan: women and men at equal risk. Am Heart J 2005;150:221-6.

44. Khushk WA, Fatmi Z, White F, et al. Health and social impacts of improved stoves on rural women: a pilot intervention in Sindh, Pakistan. Indoor Air 2005;15:311-6.

45. Castelli WP. Epidemiology of coronary heart disease: the Framingham study. Am J Med 1984;76:4-12.
46. Gordon T, Kannel WB, Hjortland MC, et al. Menopause and coronary heart disease. The Framingham study. Ann Intern Med 1978;89:157-61.

47. Hameed K, Kadir M, Gibson T, et al. The frequency of known diabetes, hypertension and ischaemic heart disease in affluent and poor urban populations of Karachi, Pakistan. Diabet Med 1995;12:500-3.

48. Ali MK, Bhaskarapillai B, Shivashankar R, et al. Socioeconomic status and cardiovascular risk in urban South Asia: the CARRS study. Eur J Prev Cardiol 2016;23:408-19.

49. Hubert HB, Feinleib M, McNamara PM, et al. Obesity as an independent risk factor for cardiovascular disease: a 26-year follow-up of participants in the Framingham heart study. Circulation 1983:67:968-77.

50. Todd Miller M, Lavie CJ, White CJ. Impact of obesity on the pathogenesis and prognosis of coronary heart disease. $J$ Cardiometab Syndr 2008;3:162-7.

51. Prospective Studies Collaboration. Age-Specific relevance of usual blood pressure to vascular mortality: a meta-analysis of individual data for one million adults in 61 prospective studies. The Lancet 2002;360:1903-13.

52. Yusuf S, Hawken S, Ôunpuu S, et al. Obesity and the risk of myocardial infarction in 27000 participants from 52 countries: a case-control study. The Lancet 2005;366:1640-9.

53. The World Health Report 2002:. Reducing risks, promoting healthy life. Geneva: World Health Organization, 2002.

54. Chowdhury R, Warnakula S, Kunutsor S, et al. Association of dietary, circulating, and supplement fatty acids with coronary risk: a systematic review and meta-analysis. Ann Intern Med 2014;160:398-406.

55. Huxley RR, Woodward M. Cigarette smoking as a risk factor for coronary heart disease in women compared with men: a systematic review and meta-analysis of prospective cohort studies. The Lancet 2011;378:1297-305.

56. Global Adult Tobacco Survey. Pakistan Fact sheet, 2014. Available: http://www.who.int/tobacco/surveillance/survey/gats/pakfactsheet. pdf 